\title{
Perceived differences between intensivists and infectious diseases consultants facing antimicrobial resistance: a global cross-sectional survey
}

\author{
Jordi Rello ${ }^{1,2}$ (1) Vandana Kalwaje Eshwara ${ }^{3} \cdot$ Andrew Conway-Morris $^{4} \cdot$ Leonel Lagunes $^{5} \cdot$ Joana Alves $^{6}$. \\ Emine Alp ${ }^{7}$. Zhongheng Zhang $^{8} \cdot$ Mervyn Mer $^{9} \cdot$ TOTEM Study Investigators $^{2}$
}

Received: 31 January 2019 / Accepted: 5 March 2019 / Published online: 21 March 2019

(C) Springer-Verlag GmbH Germany, part of Springer Nature 2019

\begin{abstract}
To identify differences in perception on multi-drug-resistant (MDR) organisms and their management at intensive care units (ICU). A cross-sectional survey was conducted. A proposal addressing a pathogen priority list (PPL) for ICU, arising from the TOTEM study, was compared with a sample of global experts in infections in critically ill patients. The survey was responded by 129 experts. Globally, ESBL Enterobacteriaceae, followed by carbapenem-resistant Acinetobacter baumannii and carbapenemresistant Klebsiella pneumoniae, were the main concerns. Some differences in opinion were identified between 63 (49\%) ICU physicians (ICU/anesthesiology) and 43 (33\%) infectious disease consultants (ID physicians/microbiologists). The pathogens most concerning in the ICU for intensivists were ESBL Enterobacteriaceae (38\%) versus carbapenem-resistant A. baumannii $(48.3 \%)$ for ID consultants, $(p<0.05)$. Increasing number of ID consultants over intensivists ( $26 \%$ vs $14 \%)$ reported difficulty in choosing initial therapy for carbapenem-resistant $A$. baumannii. For intensivists, the urgent measures to limit development of antibiotic resistance were headed by cohort measures $(26.3 \%)$ versus increasing nurse/patient ratio (32.5\%) for ID consultants, $(p<0.05)$. Regarding effectiveness to prevent MDR development and spread, education programs $(42.4 \%)$ were the priority for intensivists versus external consultation (35.7\%) for ID consultants. Finally, both groups agreed that carbapenem resistance was the most pressing concern $(>70 \%)$ regarding emerging resistance. Differences in priorities regarding organisms, infection control practices, and educational priorities were visualized between ID/clinical microbiologists and ICU/anesthesiologists. Multidisciplinary collaboration is required to achieve best care for ICU patients with severe infections.
\end{abstract}

Keywords Multidrug-resistant bacteria $\cdot$ Infection control $\cdot$ Colonization $\cdot$ Prevention $\cdot$ Antimicrobials $\cdot$ Intensive care $\cdot$ Sepsis

JR and VKE contributed equally as first authors.

Electronic supplementary material The online version of this article (https://doi.org/10.1007/s10096-019-03530-1) contains supplementary material, which is available to authorized users.

Jordi Rello

jrello@ crips.es

1 CIBER de Enfermedades Respiratorias, CIBERES, Barcelona, Spain

2 Vall d'Hebron Institut of Research (VHIR), Barcelona, Spain

3 Department of Microbiology, Kasturba Medical College, Manipal Academy of Higher Education, Manipal, India

4 Division of Anaesthesia, Department of Medicine, University of Cambridge, Cambridge, UK

5 Intensive Care Department, San Luis Potosi, Mexico
6 Infectious Diseases, Braga Hospital Center, Braga, Portugal

7 Department of Infectious Diseases and Clinical Microbiology, Medical Faculty, Erciyes University, Kayseri, Turkey

8 Department of Emergency Medicine, Sir Run-Run Shaw Hospital, Zhejiang University School of Medicine, Hangzhou, China

9 Department of Medicine, Divisions of Critical Care and Pulmonology, Charlotte Maxeke Johannesburg Academic Hospital and Faculty of Heath Sciences, University of the Witwatersrand, Johannesburg, South Africa 


\section{Introduction}

The World Health Organization (WHO) proposed a global priority pathogen list (PPL) of multidrug-resistant (MDR) bacteria [1]. However, critically ill patients are particularly susceptible to infections arising from MDR bacteria [2], and a critical care specific list of PPL has been recently reported in TOTEM study [3]. The scope was to identify the most important resistant bacteria for intensive care units (ICU) and their challenges. In this cross-sectional survey, we assessed whether these perceptions were validated by a global sample of professionals with expertise in severe infections. The secondary objective was to prioritize the list to focus efforts proportionately according to perceived clinical need. The hypothesis was that differences in perception on MDR organisms and their management occur and might be associated with the primary training background and geographic differences.

\section{Methods}

A steering committee (Appendix 2) with experience of identification, prevention, and treatment of MDR bacteria in critically ill patients developed and refined the study protocol and selection of pathogens. Mycobacteria, rickettsia, viruses, and parasites were excluded. MDR bacteria was defined as nonsusceptibility to at least one agent in $\geq 3$ antimicrobial categories [4]. The study group was represented by intensivists, anesthesiologists, clinical microbiologists, and infectious disease (ID) consultants with experience in ICU settings (Table S1, supplemental material). Pediatric and neonatal intensive care units (ICUs) were excluded.

The survey was performed using an electronic platform (SurveyMonkey®) and was distributed by invitation from members of the Steering Committee in February 2018. The survey was an online questionnaire requiring no patientspecific data, and thus, the need for research ethics committee approval and informed consent were waived. The study protocol and questionnaire were published elsewhere [5].

\section{Statistical analysis}

Analysis by Chi-square test (or Fisher's exact test when appropriate) was performed to evaluate potential associations. A two-tailed $P$ value less than 0.05 was considered statistically significant.

\section{Results}

The cross-sectional survey was completed by 129 respondents. The overall representation from within and outside Europe was $54 \%$ and $46 \%$ while the ICU practitioners (intensivists and anesthesiologists) constituted for 58\% and $42 \%$, respectively. Distribution according to regions, respondents, and IC characteristics are listed in Tables S1 and S2 (supplemental material).

Globally, extended spectrum beta-lactamase (ESBL) Enterobacteriaceae, followed by carbapenem-resistant (CR) Acinetobacter baumannii and CR Klebsiella pneumoniae were the main concerns. The mortality rankings of the organisms, therapy concerns, and opinion on measures to prevent emergence and spread of MDR are detailed in Table 1. Some differences in opinion were identified between 63 (49\%) ICU physicians (ICU/anesthesiology) and 43 (33\%) infectious disease consultants (ID physicians/microbiologists) (Table 1). The pathogens most concerning in the ICU for intensivists were ESBL Enterobacteriaceae (38\%) versus CR A. baumannii $(48.3 \%)$ for ID consultants, $(p<0.05)$. Increasing number of ID consultants over intensivists (26\% vs $14 \%$ ) reported difficulty in choosing initial therapy for CR A. baumannii. For intensivists, the urgent measures to limit development of antibiotic resistance were headed by cohort measures $(26.3 \%)$ versus increasing nurse/patient ratio (32.5\%) for ID consultants $(p<0.05)$. Regarding effectiveness to prevent MDR development and spread, education programs $(42.4 \%)$ were the priority for intensivists versus external consultation (35.7\%) for ID consultants. Finally, both groups agreed that carbapenem resistance was the most pressing concern regarding emerging resistance $(72.9 \%$ versus $77.5 \%$, $p>0.20$ ). All these results are detailed in Table 1.

Global top five organism by site and differences between geographic regions ranks according most common sites involving MDR pathogens in ICUs are shown in Table 2. The details of practiced preventive measures to limit the MDR organisms are reported in Tables S1 and S2, supplemental section.

\section{Discussion}

Our findings emphasize the global concern regarding Gramnegative bacteria, although Gram-positive organisms dominated concern regarding community-acquired pneumonia and CSSI. Differences between intensivists and ID/clinical microbiologists and regional differences in priority pathogens and strategies are important observations.

Carbapenem-resistant organisms were indisputably perceived as highest threat for mortality, treatability, and cost. In addition, the results support the difficulty faced in managing MDR P. aeruginosa infections in ICUs [6]. Mortality by $\mathrm{CR}$ organisms is contributed particularly by the nonavailability of effective drugs rather than increased virulence [7-9]. Adequacy of antimicrobial therapy, but not pathogen resistance pattern, impacted attributable mortality thus indicating the grim situation arising from the failing antibiotic pipeline [10]. The increased risk of mortality was strongly evident 
Table 1 Characteristics of the answers to TOTEM items and differences between primary specialty ICU staff versus ID consultants

\begin{tabular}{|c|c|c|c|c|}
\hline Study variables & All 129 & $\begin{array}{l}\mathrm{ICU}^{\mathrm{a}} 63 \\
(49 \%)\end{array}$ & $\begin{array}{l}\mathrm{ID}^{\mathrm{b}} 43 \\
(33 \%)\end{array}$ & $\begin{array}{l}P \\
\text { value* }^{*}\end{array}$ \\
\hline \multicolumn{5}{|l|}{ Main concern in your ICU } \\
\hline $\begin{array}{l}\text { Extended-spectrum beta-lactamase producing } \\
\text { Enterobacteriaceae (ESBL). }\end{array}$ & $42(32.6)$ & $24(38.1)$ & $8(18.3)$ & 0.003 \\
\hline Carbapenem-resistant Acinetobacter baumannii. & $38(29.5)$ & $10(15.9)$ & $21(48.3)$ & 0.001 \\
\hline Carbapenemase expressing Klebsiella pneumoniae (KPC). & $32(24.8)$ & $18(28.6)$ & $11(25.6)$ & 0.956 \\
\hline Carbapenem-resistant Pseudomonas aeruginosa. & $12(9.3)$ & $8(12.7)$ & $2(9.7)$ & 0.762 \\
\hline $\begin{array}{l}\text { Oxacillin/methicillin-resistant Staphylococcus aureus } \\
\text { (MRSA). }\end{array}$ & $2(1.6)$ & $2(3.2)$ & - & - \\
\hline \multicolumn{5}{|l|}{ Urgent measures to limit development of antibiotic resistance } \\
\hline Increase nurse/HCP ratio & $26(20.1)$ & $9(16.1)$ & $12(32.5)$ & 0.116 \\
\hline De-escalation therapies & $25(19.3)$ & $13(21.3)$ & $7(16.3)$ & 0.044 \\
\hline ID consultation & $24(18.6)$ & $11(18.3)$ & $9(23.7)$ & 0.012 \\
\hline Cohort measures & $22(17)$ & $15(26.3)$ & $5(12.8)$ & 0.184 \\
\hline Formulary restriction & $20(15.5)$ & $9(15)$ & $7(16.3)$ & 0.704 \\
\hline \multicolumn{5}{|c|}{ Effective measures to prevent MDR development and spread } \\
\hline Education programs & $42(32.5)$ & $24(42.4)$ & $12(30.8)$ & 0.261 \\
\hline Antibiotic de-escalation & $28(21.7)$ & $14(24.1)$ & $6(15.8)$ & 0.089 \\
\hline ID consultation & $24(18.6)$ & $8(13.8)$ & $15(35.7)$ & 0.001 \\
\hline Formulary restriction & $19(14.7)$ & $9(15.3)$ & $6(14.6)$ & 0.778 \\
\hline Cycling of antibiotics & $6(4.6)$ & $3(5.6)$ & $1(2.4)$ & 0.101 \\
\hline \multicolumn{5}{|l|}{ Concern for emerging resistance to antibiotics } \\
\hline Carbapenem & $84(65.1)$ & $43(72.4)$ & $31(77.5)$ & 0.609 \\
\hline Beta Lactam inhibitors & $13(10)$ & $7(11.9)$ & $1(2.4)$ & 0.165 \\
\hline Quinolones & $10(7.7)$ & $6(10.2)$ & $3(7.7)$ & 0.693 \\
\hline 3rd and 4th generation cephalosporins & $9(6.9)$ & $1(1.7)$ & $3(7.7)$ & 0.024 \\
\hline Glycopeptides & $6(4.6)$ & $3(5.1)$ & $(4.7)$ & 0.264 \\
\hline \multicolumn{5}{|l|}{ Difficulty for adequate initial treatment } \\
\hline Multidrug-resistant Pseudomonas aeruginosa & $31(24)$ & $16(32)$ & $14(36.8)$ & 0.797 \\
\hline Carbapenemase expressing Klebsiella pneumoniae (KPC) & $25(19.3)$ & $9(18.4)$ & $10(11.5)$ & 0,335 \\
\hline Carbapenem-resistant Acinetobacter baumannii & $22(17)$ & $7(14.3)$ & $11(26.2)$ & 0,082 \\
\hline $\begin{array}{l}\text { Oxacillin/methicillin-resistant Staphylococcus aureus } \\
\text { (MRSA). }\end{array}$ & $12(9.3)$ & $4(7.8)$ & $3(7.7)$ & 0.890 \\
\hline Vancomycin-resistant Enterococci (VRE) & $6(4.6)$ & $4(7.8)$ & $1(2.6)$ & 0.850 \\
\hline Carbapenem-resistant Pseudomonas aeruginosa & $6(4.6)$ & $4(7.8)$ & $1(2.6)$ & 0.753 \\
\hline Extended-spectrum beta-lactamase Klebsiella pneumoniae & $5(3.8)$ & $2(4.2)$ & - & 0.257 \\
\hline Extended-spectrum beta-lactamase Escherichia coli & $5(3.8)$ & $3(6)$ & $1(2,6)$ & 0.042 \\
\hline TMP/SMX-resistant Stenotrophomonas maltophilia & $5(3.8)$ & $4(7.8)$ & $1(2.6)$ & 0.712 \\
\hline Extended-spectrum beta-lactamase Serratia spp & $1(0.8)$ & $1(2.1)$ & - & 0.836 \\
\hline
\end{tabular}

${ }^{a}$ Anesthesia or intensive care

${ }^{\mathrm{b}}$ Infectious disease/internal medicine or clinical microbiology, * Significant $<0.05$ in Asia [11] with variations in carbapenemase production across different regions [12]. Currently, the biggest gap exists in the investigational pipeline for compounds active against CR A. baumannii. Our findings suggest that this organism is of major concern, despite it being conventionally considered low virulence [13].

Importantly, issues contributing to misuse of existing antibiotics need serious attention. Lack of suitable rapid diagnostics and non-availability in a timely manner is a major impediment in appropriately using antibiotics [14, 15]. Our survey reinforces the differential prevalence of MDR bacteria by site of infection and the importance of recording this when undertaking surveillance programs.

WHO reports estimate that approximately $30 \%$ of ICU patients are affected by at healthcare-associated infections [16]. Several reports suggest the lack of surveillance data having a 
Table 2 Rank of the most commonly reported pathogens in 2017 in participating ICUs according to specific infection sites

\begin{tabular}{|c|c|c|c|c|c|c|}
\hline Infections and associated pathogens & $N(\%)$ & $\begin{array}{l}\text { Overall } \\
\text { rank }\end{array}$ & Africa & Europe & Asia & America \\
\hline \multicolumn{7}{|l|}{ Community acquired pneumonia } \\
\hline $\begin{array}{l}\text { Macrolide-resistant Streptococcus } \\
\text { pneumoniae }\end{array}$ & $45(34.9)$ & 1 & 1 & 1 & 1 & 4 \\
\hline $\begin{array}{l}\text { 3rd generation cephalosporin-resistant } \\
\text { Enterobacteriaceae }\end{array}$ & $22(17)$ & 2 & 3 & 3 & 2 & 1 \\
\hline $\begin{array}{l}\text { Quinolones-resistant } P \text { seudomonas } \\
\text { aeruginosa }\end{array}$ & $21(16.3)$ & 3 & 4 & 2 & 3 & 2 \\
\hline $\begin{array}{l}\text { Oxacillin/methicillin-resistant } \\
\text { Staphylococcus aureus (MRSA) }\end{array}$ & $15(11.6)$ & 4 & 5 & 5 & 4 & 3 \\
\hline $\begin{array}{l}\text { 3rd generation cephalosporin-resistant } \\
\text { Streptococcus pneumoniae }\end{array}$ & $11(8.5)$ & 5 & 2 & 4 & 5 & 5 \\
\hline \multicolumn{7}{|c|}{ Hospital-acquired pneumonia/ventilator-associated pneumonia } \\
\hline $\begin{array}{l}\text { Carbapenem-resistant Acinetobacter } \\
\text { baumannii }\end{array}$ & $42(32.5)$ & 1 & 3 & 1 & 1 & 1 \\
\hline $\begin{array}{l}\text { Multidrug-resistant Pseudomonas } \\
\text { aeruginosa }\end{array}$ & $22(17)$ & 2 & 4 & 4 & 2 & 4 \\
\hline $\begin{array}{l}\text { Carbapenem-resistant Klebsiella } \\
\text { pneumonia }\end{array}$ & $21(16.3)$ & 3 & 1 & 2 & 3 & 2 \\
\hline $\begin{array}{l}\text { Carbapenem-resistant } P \text { seudomonas } \\
\text { aeruginosa }\end{array}$ & $17(13.2)$ & 4 & 2 & 3 & 4 & 3 \\
\hline $\begin{array}{l}\text { Oxacillin/methicillin-resistant } \\
\text { Staphylococcus aureus (MRSA) }\end{array}$ & $16(12.4)$ & 5 & 5 & 5 & 5 & 5 \\
\hline \multicolumn{7}{|l|}{ Intra-abdominal infection } \\
\hline Multidrug-resistant Escherichia coli & $58(44.9)$ & 1 & 1 & 1 & 1 & 1 \\
\hline Vancomycin-resistant Enterococci & $17(13.2)$ & 2 & 5 & 5 & 5 & 4 \\
\hline $\begin{array}{l}\text { Carbapenem-resistant Klebsiella } \\
\text { pneumoniae }\end{array}$ & $15(11.6)$ & 3 & 2 & 3 & 2 & 3 \\
\hline $\begin{array}{l}\text { Multidrug-resistant Pseudomonas } \\
\text { aeruginosa }\end{array}$ & $13(10)$ & 4 & 4 & 2 & 3 & 2 \\
\hline $\begin{array}{l}\text { Carbapenem-resistant Acinetobacter } \\
\text { baumannii }\end{array}$ & $12(9.3)$ & 5 & 3 & 4 & 4 & 5 \\
\hline \multicolumn{7}{|l|}{ Skin and soft tissue infections } \\
\hline $\begin{array}{l}\text { Oxacillin/methicillin-resistant } \\
\text { Staphylococcus aureus (MRSA) }\end{array}$ & $72(55.8)$ & 1 & 1 & 1 & 1 & 1 \\
\hline Multidrug-resistant Escherichia coli & $17(13.2)$ & 2 & 2 & 3 & 2 & 2 \\
\hline $\begin{array}{l}\text { Multidrug-resistant Pseudomonas } \\
\text { aeruginosa }\end{array}$ & $16(12.4)$ & 3 & 3 & 2 & 3 & 3 \\
\hline $\begin{array}{l}\text { Carbapenem-resistant Klebsiella } \\
\text { pneumoniae }\end{array}$ & $8(6.2)$ & 4 & 4 & 4 & 4 & 4 \\
\hline Vancomycin-resistant Enterococci & $4(3.1)$ & 5 & 5 & 5 & 5 & 5 \\
\hline \multicolumn{7}{|l|}{ Catheter-associated bacteremia } \\
\hline $\begin{array}{l}\text { Oxacillin/methicillin-resistant } \\
\text { Staphylococcus aureus (MRSA) }\end{array}$ & $48(37.2)$ & 1 & 1 & 1 & 1 & 1 \\
\hline Multidrug-resistant Escherichia coli & $28(21.7)$ & 2 & 2 & 2 & 4 & 2 \\
\hline $\begin{array}{l}\text { Carbapenem-resistant Klebsiella } \\
\text { pneumoniae }\end{array}$ & $22(17)$ & 3 & 3 & 4 & 2 & 3 \\
\hline $\begin{array}{l}\text { Multidrug-resistant Pseudomonas } \\
\text { aeruginosa }\end{array}$ & $12(9.3)$ & 4 & 4 & 3 & 3 & 4 \\
\hline Vancomycin-resistant Enterococci & $4(3.1)$ & 5 & 5 & 5 & 5 & 5 \\
\hline
\end{tabular}

negative influence on the implementation of preventive measures [17-21]. Two world-wide ICU infection prevalence studies in a span of 10 years have demonstrated $20 \%$ increase in prevalence $[22,23]$. Accompanying this rise in infections is a parallel increase in antimicrobial resistance rates, thus changing the status from MDR to extreme drug resistance (XDR).
We identified apparent differences in resistant organism prevalence by site of infection and geographic location. MRSA was increasingly common in CSSIs and devicerelated BSIs. Among Asian participants, CR $K$. pneumoniae was the second most commonly reported cause of device-related BSIs. Macrolide-resistant 
S. pneumoniae was perceived with lower priority in America, perhaps because the predominant mechanism of resistance is different from other regions. Similarly, CR K. pneumoniae was perceived as more important in Africa. Regional priorities for different infectious sites were reported to be similar among participants with minimal variations. Interestingly, few participants in the survey felt that adequate initial treatment for $C R$ $P$. aeruginosa was difficult, although this organism featured in the top four priority organisms in the preceding MCDA analysis [3]. This difference might be due to the perception of availability of colistin and aminoglycosides for therapy, despite recent evidence suggesting that the efficacy of these choices is similar to inappropriate therapy in clinical practice [6].

Overall, the current opinion from the survey highlights the dominant burden of Gram-negative bacterial infections over the Gram-positive infection in critical care settings. Although rates of MRSA bacteremia are declining in Europe, the occurrence of SSIs and other serious infections by MRSA are still high [24]. USA reports the opposite trend that is observed in Europe [25]. Our results reflect these trends, likely due to higher representation of European colleagues.

Our results bring attention to the variations in opinions of intensive care and ID physicians about issues such as occurrence, management, and containment of MDR infections in ICUs that might have implications on patient care. However, there was an overall consensus on components of antimicrobial stewardship (AMS) and infection prevention measures for confronting MDR infections. Interestingly, intensivists did not consider ID consultation as a priority measure to reduce antimicrobial resistance. The difference in perception might probably arise due to the non-availability of ID round the clock and their focus on the overall patient status rather than the antibiotic resistance and selection pressures. Moreover, the difficulty in differentiating colonization and true infection also contributes to differences in perceptions towards management of MDR organisms which could not be assessed in the current survey.

There are several limitations to this study. Although survey respondents came from across the globe, they represent only a small fraction of clinicians and units care for critically ill patients and universal coverage of nations was not achieved. National representation did not correlate with relative population size, and we could not assess regional variation in MDR bacteria at a national or regional level. Neither were we able to examine differences between patient types (for instance cardiac, burns, or neuro-trauma) and our findings are restricted to adult populations. Although our survey was largely focused on health-care-acquired infections, community-acquired MDR organisms in pneumonia were enquired about although not community-acquired infections at other sites.

\section{Conclusions}

The pathogens most concerning in the ICU for intensivists were ESBL Enterobacteriaceae versus CR A. baumannii for ID consultants. Differences in priorities regarding organisms, infection control practices, and educational priorities were visualized between ID/clinical microbiologists and ICU/anesthesiologists. Overall, both agree on concerns on resistant Gram-negative organisms. Need of team working is required to address best care for ICU subjects with severe infections.

Acknowledgements The study was performed as part of an Observership Grant (Vandana KE) from the European Society of Clinical Microbiology and Infectious Diseases, Basel, Switzerland. We appreciate comments in the design from Nieves Larrosa, Barcelona, Spain. The study was funded in part by Centro de Investigacion Biomedica en Red de Enfermedades Respiratorias (CIBERES), Instituto de Salud Carlos III, Madrid, Spain. We thank the study group investigators for their valuable support.

Funding The study was funded in part by Centro de Investigacion Biomedica en Red de Enfermedades Respiratorias (CIBERES), Instituto de Salud Carlos III, Madrid, Spain and Observership Programme from ESCMID, Basel, Switzerland.

\section{Compliance with ethical standards}

Conflicts of interest Dr. Rello served in the speaker's bureau or consultant for Pfizer, Anchoagen, ROCHE. The remaining authors have no conflicts of interest to declare.

Ethical approval/informed consent Not required.

\section{Appendix 1. TOTEM Study Investigators}

Argentina: Luna CM, Reina R; Bulgaria: Dobrevska R; China: Deng H, Leiqing L, Liu L, 温, 沈延飞, LX, Wang D, Yuetian Y, Zhang G, Zh Zhang, Zheng C, YW, ZRYHC; Colombia: Del Rio G; Dominican Republic: Rojas JN; Ethiopia: Amare D. France: Alfandri S, Argemi X, Kernies S, Lesprit P: Greece: Arvanitik K, Papanikolaou M, Tsigou E, Soultati I, Platsouka E, Katsiari M, Nikolaou C, Tsiodras S; Italy: Antonelli M, Cascio A, Dellamonica J, DiPascale G, Garofalo E, Girardis M, Leone D; India: Vandana KE, Kaniyarakkal V, Munim F, Nath S, Patil S, Suchitra U, Israel: Yahav D; Kenya: Misango DO; Kosovo:GecajGashi A; Kuwait: Rotimi V; Mexico: Aguilar D, AraujoMelendez J, Franco-Zendejas R, Lagunes L, Lemus J, Perales Martinez DE, Rivera Chavez M; Netherlands: Schouten J; Oman: Khamis F; Pakistan: Nizamuddin S, Portugal: Santos L, Santos-Ribeiro E; South Africa: Alekar S, Baker D, Ballot D, Black V, Bhamjee S, Brannigan L, Hunt IA, Kotze J, Lowman W, Levy B, Mer M, Morar R,Michell W, Nana T, Pahad H, Tsai M, Schleicher GK, Shaddock E, Shoul E, Smith C, Richards GA, Van der Merwe L, Welkovics N; Spain: Borges M, 
Diaz E, J Garnacho-Montero, Maseda E, Mañez R, Rello J, Samso E, Serrano R, Sole-Violan J, Vidaur L, Zaragoza R; Thailand: Wongsurakiat P; Turkey: Abravci N, Akbudak I, Akkoyunlu Y, Altındiş M, Aydin DÇelebi G, Emel A, Alp E, Erdem H, Gulden E, Guner R, Kızmaz Y, Yalçin A, Kepenek E, Sener A, Tekin R, Tulek N, Ulu, Unuvar G; Romania: Miftode E; United Kingdom: Buckley J, Conway-Morris A, Dunn M, Hall A,Hobrok M, Felton T, Fletcher S, Marshall B, McConnell H, McKee R, McAuley D, McFie C, Morton B, Naisbitt J, Rooney K, Szakmany T, Yates B, Zochios V; USA: Richard G. Wunderink; Venezuela: Von der Osten J

\section{Appendix 2- Steering Committee members}

Jordi Rello, Spain (Chair); Joana Alves, Portugal; Leonel Lagunes, Mexico; Nieves Larrosa, Spain; Mervyn Mer, South Africa; Emine Alp, Turkey; Zhongheng Zhang, China.

\section{References}

1. WHO (2017) Prioritization of pathogens to guide discovery, research and development of new antibiotics for drug resistant bacterial infections, including tuberculosis. Essent Med Heal Prod 88. doi:WHO reference number: WHO/EMP/IAU/2017.12

2. Poulakou G, Matthaiou DK, Bassetti M, Erdem H, Dimopoulos G, Curcio DJ et al (2017) "Salvage treatment" for infections by extensively- and pan-drug-resistant pathogens is common and often sub-optimal. Intensive Care Med 43:1164-1166

3. Rello J, Kalwaje Eshwara V, Lagunes L, Alves J, Wunderink RG, Conway-Morris A et al (2019) A global priority list of the TOp TEn resistant microorganisms (TOTEM) study at intensive care: a prioritization exercise based on multi-criteria decision analysis. Eur J Clin Microbiol Infect Dis 38:319-323

4. Magiorakos A-P, Srinivasan A, Carey RB, Carmeli Y, Falagas ME, Giske CG et al (2012) Multidrug-resistant, extensively drugresistant and pandrugresistant bacteria: an international expert proposal for interim standard definitions for acquired resistance. Clin Microbiol Infect 18:268-281

5. Rello J, Lagunes L, Alves J, Pulcini C, Conway-Morris A, Alp E et al (2018) TOp TEn resistant microorganisms at intensive care unit: a 2018 global expert survey (TOTEM study protocol). J Emerg Crit Care Med 2:6-6

6. Borgatta B, Gattarello S, Mazo CA, Imbiscuso AT, Larrosa MN, Lujan M et al (2017) The clinical significance of pneumonia in patients with respiratory specimens harbouring multidrug-resistant Pseudomonas aeruginosa: a 5-year retrospective study following 5667 patients in four general ICUs. Eur J Clin Microbiol Infect Dis 36:2155-2163

7. Grundmann H, Glasner C, Albiger B, Aanensen DM, Tomlinson CT, Andrasević AT et al (2017) Occurrence of carbapenemaseproducing Klebsiella pneumoniae and Escherichia coli in the European survey of carbapenemase-producing Enterobacteriaceae (EuSCAPE): a prospective, multinational study. Lancet Infect Dis 17:153-163

8. Geisinger E, Isberg RR (2017) Interplay between antibiotic resistance and virulence during disease promoted by multidrug-resistant bacteria. J Infect Dis 215:S9-S17
9. Nelson RE, Slayton RB, Stevens VW, Jones MM, Khader K, Rubin MA et al (2017) Attributable mortality of healthcare-associated infections due to multidrug-resistant gram-negative bacteria and methicillin-resistant staphylococcus aureus. Infect Control Hosp Epidemiol 38:848-856

10. Adrie C, Garrouste-Orgeas M, Ibn Essaied W, Schwebel C, Darmon M, Mourvillier B et al (2017) Attributable mortality of ICU-acquired bloodstream infections: impact of the source, causative micro-organism, resistance profile and antimicrobial therapy. J Inf Secur 74:131-141

11. Zhang Y, Chen X-L, Huang A-W, Liu S-L, Liu W-J, Zhang N et al (2016) Mortality attributable to carbapenem-resistant Pseudomonas aeruginosa bacteremia: a meta-analysis of cohort studies. Emerg Microbes Infect 5:e27-e27

12. Pogue JM, Bonomo RA, Kaye KS (2019) Ceftazidime/avibactam, Meropenem/vaborbactam or both? Clinical and formulary considerations. Clin Infect Dis 68:519-524

13. Paterson DL, Harris PNA (2015) Editorial Commentary : the new Acinetobacter equation: Hypervirulence plus antibiotic resistance equals big trouble. Clin Infect Dis 61:155-156

14. Kollef MH, Burnham CAD (2017) Ventilator-associated pneumonia: the role of emerging diagnostic technologies. Semin Respir Crit Care Med 38:253-263

15. Edmiston CE, Garcia R, Barnden M, DeBaun B, Johnson HB (2018) Rapid diagnostics for bloodstream infections: a primer for infection preventionists. Am J Infect Control 46:1060-1068

16. Health care-associated infections FACT SHEET. http://www.who. int/gpsc/country_work/gpsc_ccisc_fact_sheet_en.pdf. Accessed 3 March 2019

17. Talaat M, El-Shokry M, El-Kholy J, Ismail G, Kotb S, Hafez S et al (2016) National surveillance of health care-associated infections in Egypt: developing a sustainable program in a resource-limited country. Am J Infect Control 44:1296-1301

18. Lim C, Takahashi E, Hongsuwan M, Wuthiekanun V, Thamlikitkul V, Hinjoy S et al (2016) Epidemiology and burden of multidrugresistant bacterial infection in a developing country. Elife 5. https:// doi.org/10.7554/eLife. 18082

19. Dondorp AM, Limmathurotsakul D, Ashley EA (2018) What's wrong in the control of antimicrobial resistance in critically ill patients from low- and middle-income countries? Intensive Care Med 44:79-82

20. Alp E, Damani N (2015) Healthcare-associated infections in intensive care units: epidemiology and infection control in low-tomiddle income countries. J Infect Dev Ctries 9:1040-1045

21. Iwuafor AA, Ogunsola FT, Oladele RO, Oduyebo OO, Desalu I, Egwuatu CC et al (2016) Incidence, clinical outcome and risk factors of intensive care unit infections in the Lagos University teaching hospital (LUTH), Lagos, Nigeria. PLoS One 11:e0165242. https://doi.org/10.1371/journal.pone.0165242

22. Vincent JL, Bihari DJ, Suter PM, Bruining HA, White J, NicolasChanoin MH et al (1998) The prevalence of nosocomial infection in intensive care units in Europe. Results of the European prevalence of infection in intensive care (EPIC) study. EPIC international advisory committee. JAMA 274:639-644

23. Vincent JL, Rello J, Marshall J, Silva E, Anzueto A, Martin CD et al (2009) International study of the prevalence and outcomes of infection in intensive care units. JAMA 302:2323-2329

24. Johnson AP (2011) Methicillin-resistant Staphylococcus aureus: the European landscape. J Antimicrob Chemother 66:iv43-iv48

25. Klein EY, Mojica N, Jiang W, Cosgrove SE, Septimus E, Morgan DJ et al (2017) Trends in methicillin-resistant Staphylococcus aureus hospitalizations in the United States, 2010-2014. Clin Infect Dis 65:1921-1923

Publisher's note Springer Nature remains neutral with regard to jurisdictional claims in published maps and institutional affiliations. 